\title{
YOUTH'S CONSUMPTION PATTERN OF SOCIAL NETWORKING PLATFORMS
}

\author{
Dr. Azam Jan \\ Assistant Professor \\ Department of Communication \& Media Studies \\ Hazara University \\ Mansehra - Pakistan \\ azamjancms@gmail.com \\ Dr. Tariq Anwar Khan \\ Lecturer \\ Department of Political Science \\ Hazara University \\ Mansehra - Pakistan \\ tariqanwar84@gmail.com \\ Noor Nabi Khan \\ Lecturer \\ Department of Communication \& Media Studies \\ Hazara University \\ Mansehra - Pakistan \\ noor_cms27@yahoo.com
}

\section{Abstract}

Popularity of social networking platforms has forced scholars in different disciplines to undertake research in this domain and contribute something to this new field of knowledge. The current study is a drive with regard to the stated research area. This particular paper, takes into account youths' consumption patterns of social networking media. Results of different studies found that young folk of every society spend lots of time on social media consumption. It was further revealed that majority of the youth uses social media platforms for interaction with known and unknown people. So far as gratification of needs through social media was concerned, researches originated in different parts of the world have produced somehow similar results. Most of the studies found that the young folk use 


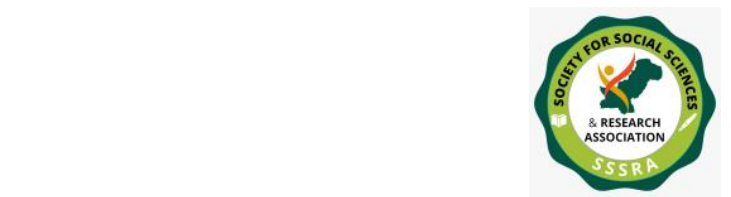

Pak. Journal of Int'L Affairs, Vol 4, Issue 4 (2021)

Youth's Consumption Pattern of Social ...

social media to satisfy their information, communication, social interaction and entertainment needs.

Key works: Social networking platforms, Youth, Consumption pattern, Needs gratification

\section{Introduction}

The young generation around the globe is reckoned as the most active users of the technology of social media. These users often prepare their own contents and share the same with other users of the technology. This activity is regarded as one of the distinctive and favourite activities of users in almost all societies of the world. The stated activity is most often reciprocated and thus the process goes on and on. The knowledgeable social media users are most likely followed by the relatively new and unskillful users. This activity on social networking platforms as observed by Benkler (2006), increases their social connections. He believes that social media users on the one hand, produce and share their own stuff and on the other hand, extract meanings of their choice out of the contents found floating online.

Defining of contents in their own way has often been found in "comments columns" of almost every SNS, especially Facebook. Here in these corners, one can see a lot of selfinterpretation rather misinterpretation of the stuff based on religions and cultures.

For example, the platforms like "The Star Wars Mashup Editor" facilitate the users to gather material of their needs and requirements out of the main stream media and do edit the same to fit in their interests. Likewise, "TheForce.net" helps its consumers to generate, prop up and collect movies of fan's choices (Schafer, 2009).

A significant boost in the use of social networking sites (SNSs) has been noted in the last decade across the planet. As mentioned by Mehmood (2013), the use of SNSs was started as a hobby by educated people, but now, it has become a universal daily routine. Within a short span of time, the internet was turned to a social networking platform from mere repository of information (Abdulahi, et al., 2014).

\section{Consumption Pattern}

There are numerous Social Networking Sites (SNSs) used by billions of people around the world for multifarious purposes. Most of the young users consume the technology on daily basis to establish relationship with real life friends and to find out new friends with similar temperament and ideas (Boyd \& Ellison, 2007; Lenhart \& Madden, 2007). 


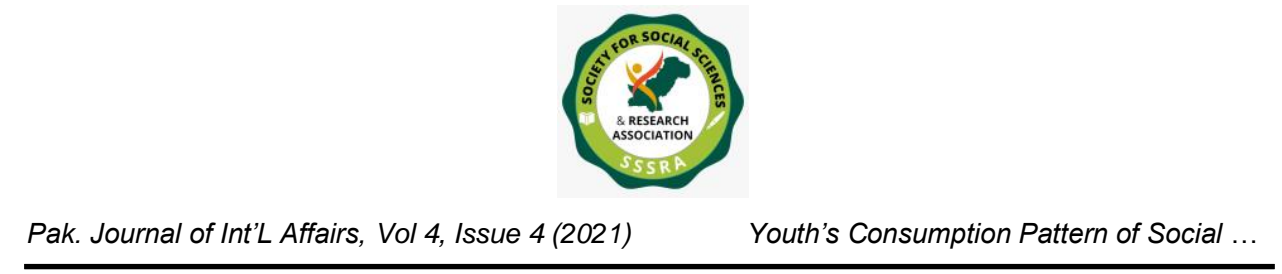

A gender based research finds that $(46 \%)$ males use social media for social interaction whereas, (44\%) of females consume perform the same activity. Nonetheless, (70\%) of comparatively old females make use of SNSs for connection with others while $(57 \%)$ percent of relatively old boys use social media to engage with others (Boyd, 2008).

Christofides, Muise, \& Desmarais, (2010) report that the youngsters consume one hour a daily on Facebook whereas, the relatively senior citizens use Facebook for spend half an hour daily. The same research finds that on average, the youngsters are having 220 Facebook friends while the elderly are having 237. The most striking result of the study was found to be observing of children Facebook usage by their parents. Around 50 percent of the parents reported to have monitored their children's use of Facebook (Christofides, Muise, \& Desmarais, 2010).

Communications through the SNSs help connect users with existing friends and members of their respective family. With the provision of full freedom of expression on social media platforms, the users freely speak out their mind and thus increase their number of new friends. The nature of information and preferences on the user's profiles normally determines the nature of interaction among the users (Posey, Lowry, Roberts, \& Ellis, 2010). This facility in turn helps users to update their profiles by posting everything about themselves and others which they consider as representative of their desired images (Amichai-Hamburger \& Vinitzky, 2010).

The invention of SNSs however, shifted the all-important trend of face to face interpersonal communication to the newly emerged computer-mediated communication. The users of the SNSs have made it a daily routine to communicate online with family members, friends, colleagues, and even unknown people through texting, emailing, instant messaging and social networking. This facility of social networking in turn has facilitated users in self-disclosure as many people found reluctant to speak out their minds in face to face settings (Adler, Rosenfeld, \& Proctor, 2010; Lenhart, et al., 2007).

The use of SNSs has been made part and parcel in almost all walks of life (Whitty, 2002 \& 2003). The usage of these technologies has penetrated so deep into human social life that one can hardly differentiate between the real life and virtual or online life. Real life activities, festivals, rituals and much more have gained more than due share in the online space. What one sees and observes in the real world is often reflected in the cyber space (Bakardjieva, 2005; Suoranta \& Lehtimaki, 2004; and Carter, 2004).

The impending role of social media in bridging people and information has been recoginsed in every field of life across the planet. But in the higher educational institutions 


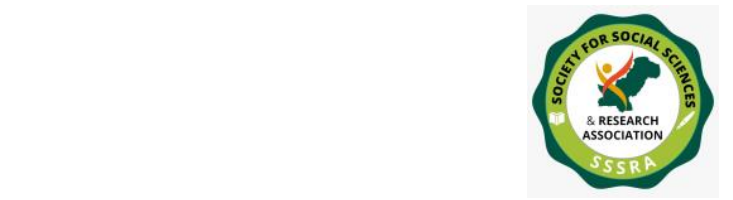

like universities, connecting of teachers and students and subsequent knowledge sharing has become the hallmark of SNSs. The student's connection with their teachers on social media with respect to knowledge sharing is thought to be a new development in the teaching and learning practice. Besides, the knowledge created by the teachers through research is shared with students by making use of this digital technology (Brown \& Adler, 2008).

Given this role, the teen agers, especially the students, rushed early to accept the technology of social networking platforms (Castells, 2001; Quan-Hasse, 2008; Livingstone \& Bober, 2005).

Students around the world are used to consume SNSs for interaction with friends, for news feeds, updating personal profiles, searching and sharing different events, sending messages and commenting on posts of their friends. Almost $49 \%$ of teen-agers are doing these activities through different SNSs (Ofcom, 2008; Dowdall, 2009). Highlighting the consumption pattern of internet among the American users, a study found that $73 \%$ of the US citizens, especially, the youth are the users of internet. The same study revealed that instant messaging has been the top most popular activity of the $92 \%$ respondents. Among them, over $20 \%$ were doing instant messaging to have interaction with friends. $(83 \%)$ of them visited entertainment websites and $(69 \%)$ were using internet to have information about their hobbies (Lenhart, Rainie, \& Lewis, 2001). Connolly (2011) research on "benefits and drawbacks of social media in education" found that $90 \%$ young students make use of at least one SNS daily. The same study indicated that the users of SNSs send as much as 65 million text- messages on daily basis (Connolly, 2011).

Aghazamani (2010) carried out a study on students' motivations for the use of Facebook. Total 595 Facebook users and students of Karlstad University, Sweden, participated in the survey. Results of the study indicated that male students spend more time on Facebook than female students. Similarly, friendship was found as the top most favorite activity among male undergraduate students. Lenhart and Madden (2007) investigated that youth use SNSs to create and maintain friendship.

The abundant facilities of online interaction with friends turn friends into close friends. The reason for this close friendship as Lenhart, et al. (2001) found was that the users feel at ease in frankly communicating to their friends on the internet than some other forms of communication. They also investigated that online interaction has improved the quality of relationships among friends. These findings are very much in line with that of West \& Turner (2007) social penetration theory. According to the theory, people come close together through initially apparent communication and then to intimate communication. 


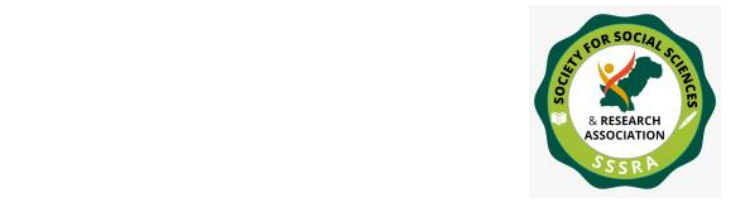

Pak. Journal of Int'L Affairs, Vol 4, Issue 4 (2021)

Youth's Consumption Pattern of Social ...

Intimacy according to Altman and Taylor is not meant to be physical in nature but it takes other dimensions like intellectual, emotional and the extent of sharing activities (pp.185189).

\section{Consumption Pattern and Demographic Differences}

There have been common observations that the demographic differences of the users in terms of age, education and gender causing variations in the activities they normally do on SNSs. A study found that interacting through instant messaging on the internet has a positive link with the level of education. The study investigated that for Grade - 4 students interaction through instant messaging was only $28 \%$, while communication through instant messaging for grade -7 to grade - 11 was $70 \%$ and $80 \%$ respectively. The same study however, recorded a negative relationship between the playing of games on the internet and the level of education. According to the findings, $89 \%$ of Grade - 4 students used to play games while only $63 \%$ of Grade - 11 students had the same activity on the internet. Likewise, the research found differences in the extent of doing activities on the net by both genders. According to the findings, $75 \%$ of females were doing their school work on internet, $68 \%$ of girls were used to do instant messaging, the same percentage $(68 \%)$ of the students were used to play games. The most used activities the study found for male students was playing games on internet. $85 \%$ of them were found engaged in playing games, $(68 \%)$ of the boys were using social media to do their school work while $63 \%$ of them were reported to have resorted to the use of instant messaging on internet (Media Awareness Network 2005).

According to the findings of the same study, students in the early stages of their study and within the early phase of adolescence take lesser interests in communicating through texting on SNSs than the students in the relatively higher grades and within the latter part of adolescence. With regard to playing games on social networking media, the younger kids are far more eager to play games than relatively senior kids. Both these findings seem to be consistent with the basic human nature of coming of age with due course of time. The findings of the research pointed out that the female students are relatively more mature in line with taking interests in studies than male students. The same has been indicated by the study that girls use social media for completing their school assignments more often than their male counter parts (Media Awareness Network 2005). In the same manner Lenhart, Purcell, Smith, \& Zickuhr, (2010) also regarded gender as one of the key variables that bearing effects on the usage pattern of social media. They noted that majority of the respondents among females users are registered users the Facebook. And most of the males have accounts in the LinkedIn. Similarly, Tufekci mentioned that female users are likely to 


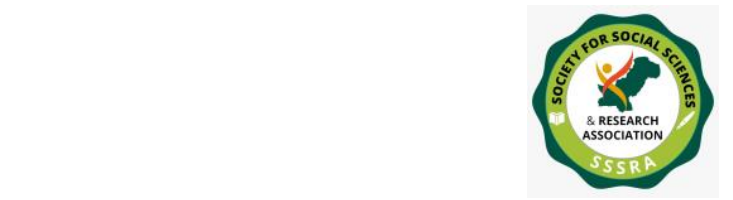

Pak. Journal of Int'L Affairs, Vol 4, Issue 4 (2021)

Youth's Consumption Pattern of Social ...

use social networking platforms four to five times more than the male users (Tufekci, 2008).

\section{Social Networking Platforms and Online Profiles}

Social networking media is playing important role in reshaping the perceptions of the young generation regarding their personal identities on the one hand, and on the other, help redesigning of their socio-cultural representation through their acts and communications (Morimoto \& Friedland, 2011). Updating of personal profiles on social networking websites have been a favourite activity of the users. They usually make use of catchy slogans, phrases, pictures, videos, audios and many more to catch up as many people as they can to create good impression of their personality. The users consciously catalog their own activities and that of others with a purpose in their mind (Miller \& Arnold, 2003). Such a profile is termed by Turkle (2011) as "an avatar of sorts" where there is less about one's real self but more about one wish to be; the contents on the profiles are more ambitious and less representative of the users self-identity (P. 180). According to Pempek, Yermolayeva, \& Calvert (2009), the users of SM create their online personal profiles from where they reach and interact with other users. They often seek and share pictures, upload and share their activities and share messages with friends. That is the reason why SNSs are getting popular with every passing day among the youth, especially among college students.

Young (2013) found that the users of Facebook make use of three tools for identity creation; "status updates, posting photographs and joining pages/groups". According to Young users update their profiles for three reasons: to look sharp and smart; to give an impression that their online acts are the true reflection of their real life; and to keep in touch with their friends. Similarly, the reasons for uploading of pictures were to look cool and attractive and to reflect their personality in a way acceptable to other users. So far as the feature of joining groups or pages was concerned, the same researcher investigated that in their early phase of Facebook usage the users happen to join almost all pages or groups as mandatory practice but after getting a substantial experience in the use of internet, they start selecting from among a lots of such groups. The basic aim of joining these pages or groups according to Young was to give an impression to the members of the group/page that $\mathrm{s} / \mathrm{he}$ has an interest in the group or page.

As the norm of increasing the number of online friends has become a symbol of online social status so self- disclosure is generally aimed at catching and extending the list of friends. According to the findings of the study of Pempek et al. (2009), on average young users have 358 friends on Facebook. In a study on Facebook friends of the students, West, 


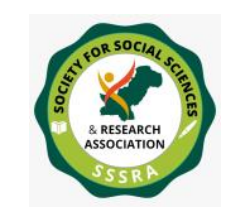

Pak. Journal of Int'L Affairs, Vol 4, Issue 4 (2021)

Youth's Consumption Pattern of Social ...

Lewis, \& Currie (2009) found the number of Facebook friends of the users to be 200 on average. According to the study most of these online friends were the people the users have remained in touch in real life before online interaction. More than 80 percent of these online friends were within the same age group. Students were found reluctant in befriending relatively elder people, especially, family members on Facebook and mentioned different reasons for avoiding contacts with them. A good number of students stated it as surrender of privacy, while a few of them were in favour of detaching online life from that of offline or real life. The study concluded that the students felt hesitation to interact with their parents. They pleaded that such an interaction can make their personal lives public which in turn can endanger their self-concept (West, Lewis, \& Currie, 2009).

The issue of the use of pseudonym has been raised by many scholars doing research on the consumption patterns of SNSs. Some of the scholars in the field take it negatively and term it as a matter of grave concern. While the opposite school of thought consider it as very useful provider of social freedom to users and thought of it as an essential part of open communications. One of such researchers Turkle (1996) upholds both points of views. In her scholarship, she sometimes declared the usage of pseudonym as important for "identity play" while in other instances she termed it as affecting the volume of interpersonal real life communications. However, one of the common opinions in support of the usage of pseudonym is that the users of SM with fake accounts can easily participate in identity assessment and "play" (Turkle, 1996). This "identity play" is eased by eliminating the self from the societal restrictions of the "embodied entity", this detachment is considered as very dominant to satisfy the split "postmodern self" (Wilson, 2007). Wilson's argument is supported by those researchers who are thought to be the supporters of creating online culture. Online culture basically accounts for free enterprise in terms of interactions and communications through online sources. The users with pseudonym can express in a better way than those who participate through their real accounts. Thus fake accounts in SNSs help free the users from social restrictions and taboos of self-disclosure (Parrish, 2002). Conversely, such a freedom from social taboos can cause ethical concerns with respect to the rights of other users (Wilson, 2007).

Fake accounts in social networking sites are created as an alternative account from where the users can discuss very sensitive and controversial issues. They very often post their own stuff on sensitive topics and make replies to comments on the same topics by making use of fake accounts.

\section{Social Networking Media and Needs Gratification of the Users}




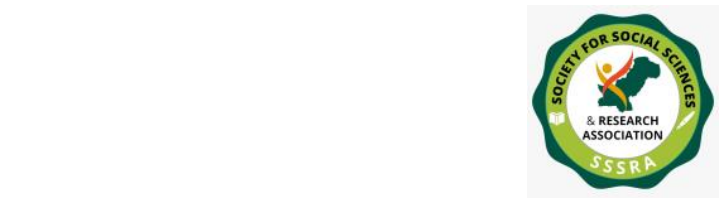

Pak. Journal of Int'L Affairs, Vol 4, Issue 4 (2021)

Youth's Consumption Pattern of Social ...

Definitions of inter personal communication have been changing with the emergence of every new technology. But the concept that communication is essential for satisfying various human socio-psychological needs remained the same. The lack of communication often results in life dissatisfaction, identity problems, premature death, undesirable relationships, and failure in academics. Scores of studies have been conducted in line with this phenomenon. One such study is that of Dhaha \& Igale (2013) who carried out an online survey to investigate the usage patterns of Facebook among Somali Youth. Three hundred and eleven people participated in it. Among them $87 \%$ respondents were male while $13 \%$ were female. Almost half of the respondents were university students between 21-25 years age. It was investigated that the participants were using Facebook to obtain needs like escape, entertainment, information, self- expression, pastime and promotion of the soft image of their country.

Hargittai (2008) conducted a survey with 1060 students as participants. He found that overall 88\% students were using SNSs. The study found that the use of SNSs helps fulfill communication needs of the users. Communication through these sites is a convenient way of staying connected with friends and family members.

The most striking feature of social networks is the gratification of user's needs according to their will. Users can interact with others within their own schedule. It's the users' option when to read and when to respond. Given this, the internet communication is termed as a private action which almost every individual usually do alone.

The facility of social networking platforms helps users to satisfy their socio-psychological needs, especially that of communicating with others. One of the advantages of SNSs usage is that interaction among users is very convenient and at the disposal of the users will. The users are often at liberty to communicate with others in times they feel at ease. The most fascinating aspect of this technology for young people is the facility of using it alone, and communication of a single user to as many people as s/he likes. This quality of social media helps disseminate information within no time. The same researchers concluded that comments on own pictures from other users is a way of receiving attention from a wide range of people indirectly. A rapid response from friends causes needs gratification and feelings of satisfaction of personal desires (Urista, Dong, \& Day, 2009).

The facility of communicating with others on SNSs has let people speak out their mind and express what the user cannot say in real life situations. According to Turkle (2011), the use of SNSs "supports an emotional style in which feelings are not fully experienced until they are communicated." 


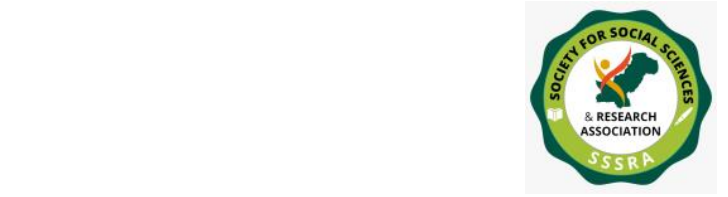

Pak. Journal of Int'L Affairs, Vol 4, Issue 4 (2021)

Youth's Consumption Pattern of Social ...

Pempek, et al. (2009) found some variations in the time spent on the usage of SM. The study found the relatively young students as more frequent users of Facebook than their senior counterparts. It was also noted that Facebook was consumed mostly to connect and communicate with their real life friends. Likewise, Sheldon (2008) mentioned that females mainly use SNSs to satisfy pastime and entertainment needs whereas, males make use of social media to search out new friends.

\section{Conclusion}

Most of the SNSs are used mainly for interaction with existing friends, new friends and family members. However, it has been observed that the users consume a lot more time on SNSs just to have a glance on the contents posted on social media without reciprocating the same. It is also found that watching and reading of the contents like those on people's timelines, news feeds, and pictures shared by other social media users was reported to be the most preferred activities of the users (Pempek, et al, 2009).

The infrastructure of SNSs provides a lot more facilities to its consumers to interact with others. But the top most beneficiaries according to Baker \& Oswald (2010) of this facility are reported to be the introverts. Shy people are mostly found avoiding interpersonal and face to face contacts thus they lack in social capital. Such people feel at ease in communicating with known and unknown individuals through these platforms and thus extend their list of best quality friends. The main reasons they mentioned were that since shy people avoid face to face discussions with people so they have lots of time to spend on line and interact with others improving on their social capital.

In a study, Tufekci (2008) investigated the relationship of social media users and non-users with that of "social grooming". Social grooming was measured in terms of "social interaction, communication, gossip, and entertainment". The results revealed that the users of SNSs gratify their needs by way of accessing their friends through searching their profiles and related activities while non-users of SNSs were found to be least interested in same activities.

The technology of SNSs provides a vibrant forum for expressing one's mind. Since the youth are the heaviest users of this technology around the globe, they leave no stone unturned in expressing and highlighting their personalities to impress other users. The users very often form personal profiles and past attractive and eye catching contents in the form of photos, information, audio-video files to attract as many users as possible. They also share information about their selves and their friends to show that they are quiet social and are capable for social acceptance in any online community. These sites provide the 
users with the facility of easy interaction and communication with friends which in turn help change their attitudes. The users, especially, the young adults speak out everything they have in their mind.

Since, most of the drivers of the technology are young so they have the facility, time, inclination and the necessary know-how for using the same. The usage of SNSs by youth has been linked with positive effects in terms of the facility of inter connectedness, communication and subsequent socialization. While a few scholars attach some adverse effects with consumption of SNSs on the ground that persistent use of social media reduce the significant inter personal contacts. This in excess use of SNSs by youth has caused great concern and the researchers are turning their heads to probing the problem. 


\section{References}

Abdulahi, Samadi, B \& Gharleghi, B. (2014). A Study on the Negative Effects of Social Networking Sites Such as Facebook among Asia Pacific University Scholars in Malaysia. International Journal of Business and Social Science, 5 (10). 133-145

Adler, R. B., Rosenfeld, L. B., \& Proctor, R. F. (2010). Interplay. Oxford: Oxford University Press.

Aghazamani, A. (2010). How do University Students Spend Their Time on Facebook? An Exploratory Study. Journal of American Science, 6 (12), 730-735.

Amichai-Hamburger, Y. \& Vinitzky, G. (2010). Social network use and personality. Computers in Human Behavior, 26 (6), 1289-1295.

Baker, L. R., \& Oswald, D. L. (2010). Shyness and online social networking services. Journal of Social \& Personal Relationships, 27(7), 873-889.

Bakardjieva, M. (2005). Internet society: The Internet in everyday life. London, UK: Sage.

Benkler, Y. (2006). The Wealth of Networks: How Social Production Transforms Markets and Freedoms. New Haven, London: Yale University Press.

Boyd, M. D. (2008). Why youth heart social network sites: The role of networked publics in teenage social life. In D. Buckingham (Ed.), Youth, identity and digital media., The

John, D. \& Catherine T., MacArthur Foundation Series on Digital Media and Learning. (pp. 119-142). USA: Massachusetts Institute of Technology (MIT) Press.

Boyd, M. D. \& Ellison, N. B. (2007). Social network sites: Definition, history, and scholarship. Journal of Computer Mediated Communication, 13 (1), 210-230.

Brown, J. S., \& Adler, R. P. (2008). Minds on Fire: Open Education, the Long Tail and Learning 2.0. Educase Review, 43 (1), 28-38.

Carter, D. M. (2004). Living in virtual communities: Making friends online. Journal of Urban Technology, 11 (3), 109-125.

Castells, M. (2001). The Internet Galaxy: Reflections on the Internet, Business, and 


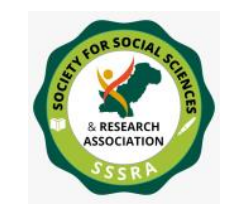

Pak. Journal of Int'L Affairs, Vol 4, Issue 4 (2021)

Youth's Consumption Pattern of Social ...

Society. Oxford, UK: Oxford University Press.

Connolly, M. (2011). Benefits and Drawbacks of Social Media in Education. Wisconsin Center for Education Research (WCER), 22 (4), 2.

Christofides, E. Muise, A. \& Desmarais, S. (2010). Privacy and Disclosure on Facebook: Youth and Adults' Information Disclosure and Perceptions of Privacy Risks. Office of the Privacy Commissioner Canada, (21-38).

Dhaha, I. S. Y. \& Igale, A. B. (2013). Facebook Usage among Somali Youth: A Test of Uses and gratification Approach. International Journal of Humanities and Social Science, 3 (3), 299-313.

Dowdall, C. (2009). Impressions, improvisations and compositions: reframing children's text production in social networks sites. Literacy, 43(2), 91-99.

Hargittai, E. (2008). Whose Space? Differences Among Users and Non-Users of Social Network Sites. Journal of Computer Mediated Communication, 13(1), 276-297.

Lenhart, A., Purcell, K., Smith, A., \& Zickuhr, K. (2010). Social media and young adults. Pew Internet and American Life Project. Retrieved from: http://www.pewinternet.org/Reports/2010/Social-Media-and-Young-Adults.aspx.

Lenhart, A., \& Madden, M. (2007). Teens, Privacy \& Online Social Networks. Pew internet and American life project report. Retrieved from Pew Internet and American Life Project website; http://www.pewinternet.org/Reports/2007/Cyberbullying.aspx

Lenhart, A., Rainie, L., \& Lewis, R. (2001). Teenage life online: The rise of the instant message generation and the internet's impact on friendship and family relationships. Washington, USA: Pew internet and American Life Project URL:

http://www.pewinternet.org/pdfs/PIP_Teens_Report.pdf [June 19, 2007].

Livingstone, S., \& Bober, M. (2005). UK Children Go Online: Final Report of Key Project Findings. ESRC, and E- society.

Media Awareness Network, (2005). Young Canadians in a wired world: Phase II Student Survey. ERIN research, Media Awareness Network URL:

http://www.mediaawareness.ca/english/research/YCWW/phaseII/upload/YCWWII_ Student_Survey.pdf [June 19, 2007]. 


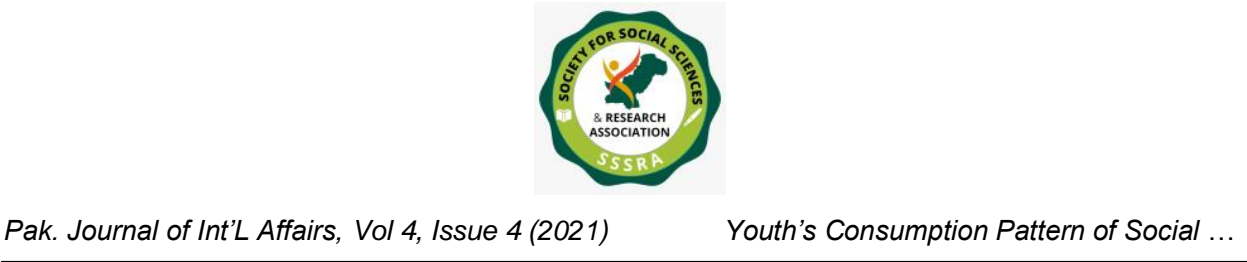

Miller, H., \& Arnold, J. (2003). Self in web home pages: Gender, identity and power in cyberspace. In G. Riva, \& C. Galimberti, (Eds., 73-94), Towards Cyber Psychology: Mind Cognitions and Society in the Internet Age. Amsterdam, Netherland: IOS Press.

Morimoto, S. A., Friedland, L. A. (2011). The Lifeworld of Youth in the Information Society. Youth \& Society, 43)2(, 549-567.

Ofcom. (2008). Social networking: A quantitative and qualitative research report into attitudes, behaviour and use. Retrieved on June 15, 2014 from: http://stakeholders.ofcom.org.uk/binaries/research/media-literacy/report1.pdf.

Parrish, R. (2002). The Changing Nature of Community. Strategies: Journals of Theory, Culture and Politics, 15 (2), 259-284.

Pempek, T. A., Yermolayeva, Y. A., \& Calvert, S. L. (2009). College students' social networking experiences on Facebook. Journal of Applied Developmental Psychology, 30(3), 227-238.

Posey, C., Lowry, P. B., Roberts, T. L., \& Ellis, T. S. (2010). Proposing the online community self-disclosure model: The case of working professionals in France and the U.K; who use online communities? European Journal of Information Systems, 19 (2), 181-195.

Quan-Hasse, A. (2008). Instant Messaging on Campus: Use and Integration in University Students' everyday Communication. The Information Society, 24 (2), 105-115.

Schafer, M. T. (2009). Participation inside: User activities between design and appropriation. In Boomen, M. V., Lammes, S., Lehmann, A., Joost Raessens, J.,\& Schafer, M. T. (eds., 147). Digital Material: Tracing New Media in Everyday Life and Technology. Amsterdam University Press.

Sheldon, P. (2008). Student favorite: Facebook and motives for its use. South western Mass Communication Journal, 23(2), 39-53.

Suoranta, J., \& Lehtimaki, H. (2004).Children in the information society. New York, USA: Peter Lang. 
Tufekci, Z. (2008). Grooming, Gossip, Facebook, and MySpace. Information, Communication \& Society, 11(4), 544-564.

Turkle, S. (2011). Alone Together: Why We Expect More From Technology and Less From Each Other. NY, USA: Basic Books.

Turkle, S. (1996). Life on the Screen: Identity in the Age of the Internet. London, UK: Weidenfeld \& Nicolson.

Urista, M. A., Dong, Q., \& Day, K. D. (2009). Explaining why young adults use MySpace and Facebook through uses and gratifications theory. Human Communication, 12(2), 215- 229.

West, A., Lewis, J., \& Currie, P. (2009). Students Facebook friends: public and private spheres. Journal of Youth Studies, 12(6), 615-627.

West, R. \& Turner, L. H. (2007). Introducing Communication Theory: Analysis and Application. (3rd ed., 423). New York, USA: McGraw Hill..

Whitty, M. T. (2003). Cyber-flirting: Playing at love. Theory and Psychology, 13 (3): 33957.

Whitty, M. T. (2002). Liar, liar! An examination of how open, supportive and honest people are in chat rooms. Computers in Human Behavior 18 (4), 343-352.

Wilson, M. (2007). Community in the abstract: a political and ethical dilemma. In B. M. Kennedy \& D. Bell. The Cyber cultures Reader, (2nd Ed) . London, UK: Routledge.

Young, K. (2013). Managing Online Identity and Diverse Social Networks on Facebook. Webology, 10 (2), 2-18 